\title{
The Integrated Ocean Prediction System (IOPS)
}

\author{
Richard A. Allard, James Kaihatu, Y. Larry Hsu \\ Naval Research Laboratory. Stennis Space Center, Mississippi USA
}

\author{
James D. Dykes \\ Naval Oceanographic Office. Stennis Space Center, Mississippi USA
}

\section{Introduction}

Knowledge of wave and surf conditions can play a major role in planning and executing a successful amphibious assault on a targeted beach (Figure 1). The dynamic surf zone is affected by waves that may have propagated from long distances (swell) and by refraction, which causes waves to become aligned with depth contours as they approach the coast. Local wind waves and tides can also change the character and width of the surf zone. Local bathymetry (e.g. beach profiles) can change dramatically due to wave action from storms. Offshore bars can form and migrate due to seasonal changes in wave dynamics and surf conditions. Accurate predictions of surf processes are dependent on models that contain the appropriate physics, and realistic environmental inputs to these models.

A wave-tide-surf modeling system has been developed to support naval operations in littoral waters. The Integrated Ocean Prediction System (IOPS) provides integrated wave information from deep to shallow water into the surf zone. IOPS is composed of four component models: (1) the Wave Action Model (WAM); (2) two shallow-water wave models (steadystate wave model, STWAVE, and the REFraction/DIFfraction Model, REFDIF); (3) two tidal models (ADvanced CIRCulation Model, ADCIRC, and the US Navy Relocatable Tide/Surge Prediction System-PCTIDES); and (4) the Navy Standard Surf Model (NSSM). Different physical processes and spatial scales affecting wave conditions across shallowwater regions are considered when these models are used. In addition, the modeling techniques delineate surf characteristics that may vary substantially along stretches of coast.

\section{System Overview}

IOPS is a component of the Rapid Ocean Analysis Modeling Evaluation Relocatable (ROAMER) System, that is designed to provide the Naval Oceanographic Office's (NAVOCEANO's) Warfighter Support Center (WSC), with the capability to set up, run, and monitor model performance using a Graphical User Interface (GUI). ROAMER is composed of a relational database in which information (grids, etc.) about each model is stored. The ROAMER system provides the user access to NAVOCEANO's DBDBV bathymetry (global 5 minute resolution) and a host of Fleet Numerical Meteorology and Oceanography Center METOC products. ROAMER is used to pull in the required input data and boundary conditions and build a script to launch the appropriate model run. The NAVOCEANO WSC utilizes the NAVOCEANO Major Shared Resource Center (MSRC), a network of computers that can support parallel codes and multi-processors.

The IOPS model suite is depicted in Figure 2. The NSSM requires four inputs: 1) shallow-water wave spectra, 2) water elevation from a tidal model, 3) beach profile(s) and 4) 10-m surface wind. The regional WAM provides directional wave spectra that are used as an offshore boundary condition for a shallow-water wave

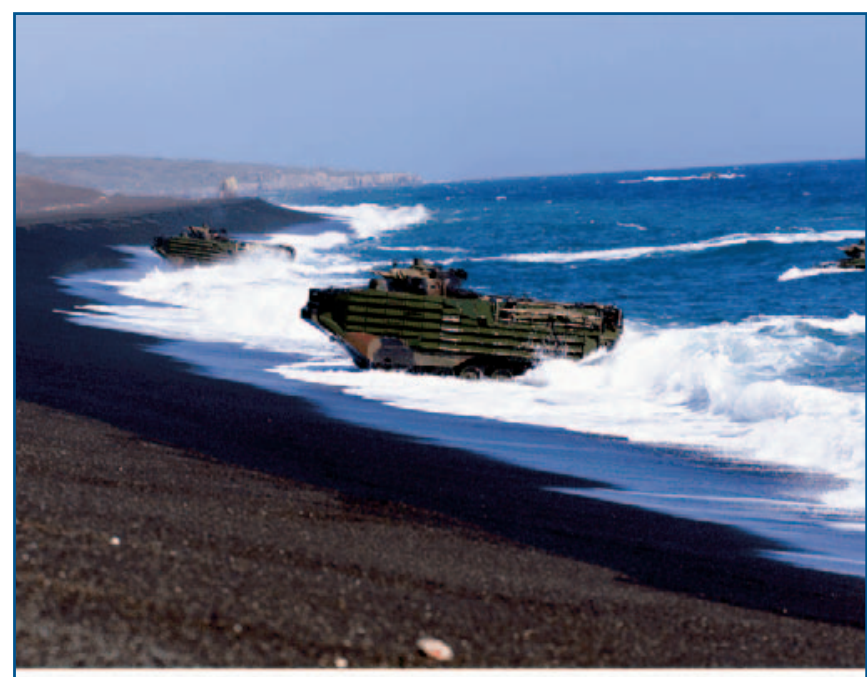

Figure 1. Assault Amphibian Vehicles from $A A V$ Platoon, Battalion Landing Team 3/1, $13^{\text {th }}$ Marine Expeditionary Unit (Special Operations Capable), made the most of their visit to Iwo Jima by landing all $A A V s$ onto Green Beach, Jan. 26, 2001. Marine photo by Sgt. M.C. Brown. 


\section{INTEGRATED OCEAN PREDICTION SYSTEM}

\section{SHALLOW- WATER SPECTRA \\ TIDES \\ BEACH PROFILES \\ WINDS}

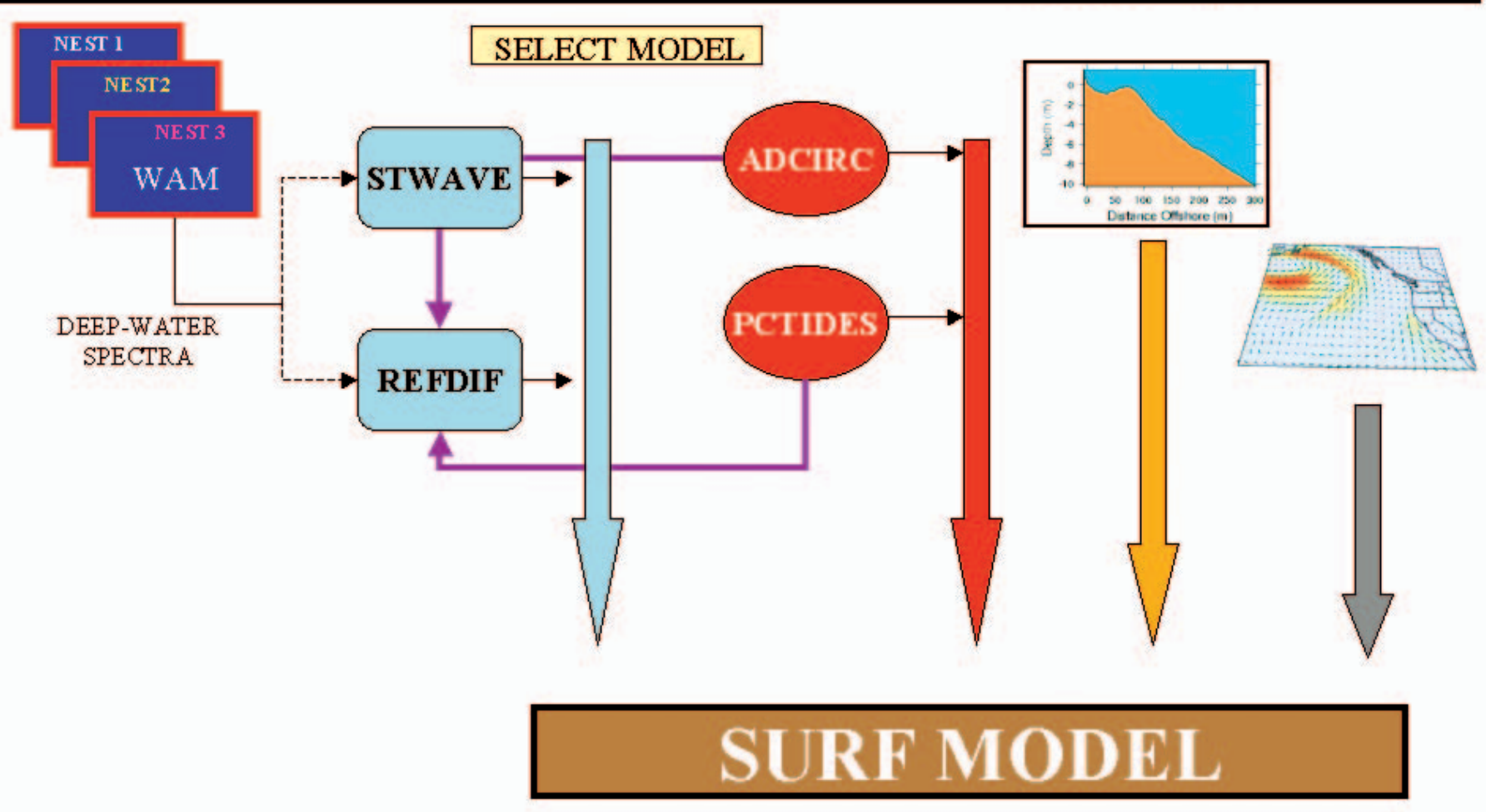

Figure 2. IOPS model components. The Navy Standard Surf Model requires four inputs: directional wave spectra from a shallow-water wave model, water elevation from a tidal prediction model, beach profiles, and wind speed and direction.

model. A tidal prediction model, which can be forced with high-resolution winds, provides tidal inputs to NSSM. Last, beach profiles and winds are passed to NSSM.

\section{WAM}

WAM (WAMDI group 1988; Komen et al., 1994) was originally developed at the Max Planck Institute for Meteorology in Hamburg, Germany, and updated by a consortium of collaborating scientists in Europe to the current version known as WAM Cycle 4. The U.S. Army Corps of Engineers Waterways Experiment Station (WES) at the Coastal Hydraulics Lab (CHL) in Vicksburg, Mississippi, adapted command files and source code for use by the U.S. Navy. At Vicksburg, efforts continue to modify WAM (Jensen et al., this issue) for more efficient parallel computing.

NAVOCEANO made further modifications to adapt the model for efficient operational processing on the NAVOCEANO MSRC. The primary computational unit for the numerical model is the Cray ScalableVector (SV1) platform, which can perform vector calculations while changing the number of processors on the fly. While WAM is coded for vector processing, the scalable aspect of the SV1 allows for running the model on as many as eight CPUs. As a result, NAVOCEANO can run a 48-hour WAM forecast for the entire globe in less than 30 minutes and has been able to run 45 separate domains around the world every 12 hours.

In addition to high throughput, it is possible to run WAM in a large variety of domains of differing shapes and sizes, due to modifications that allow for dynamic memory allocation. Using Fortran90, a single executable program can be run for any size without changing the source code and recompiling. In addition, rather than having to run a separate, individual host model to provide boundary conditions for each nest (Figure 3a), the code allows for a single host to output boundary conditions for multiple nests (Figure 3b), which can be changed on the fly. In this way model domain setup can 


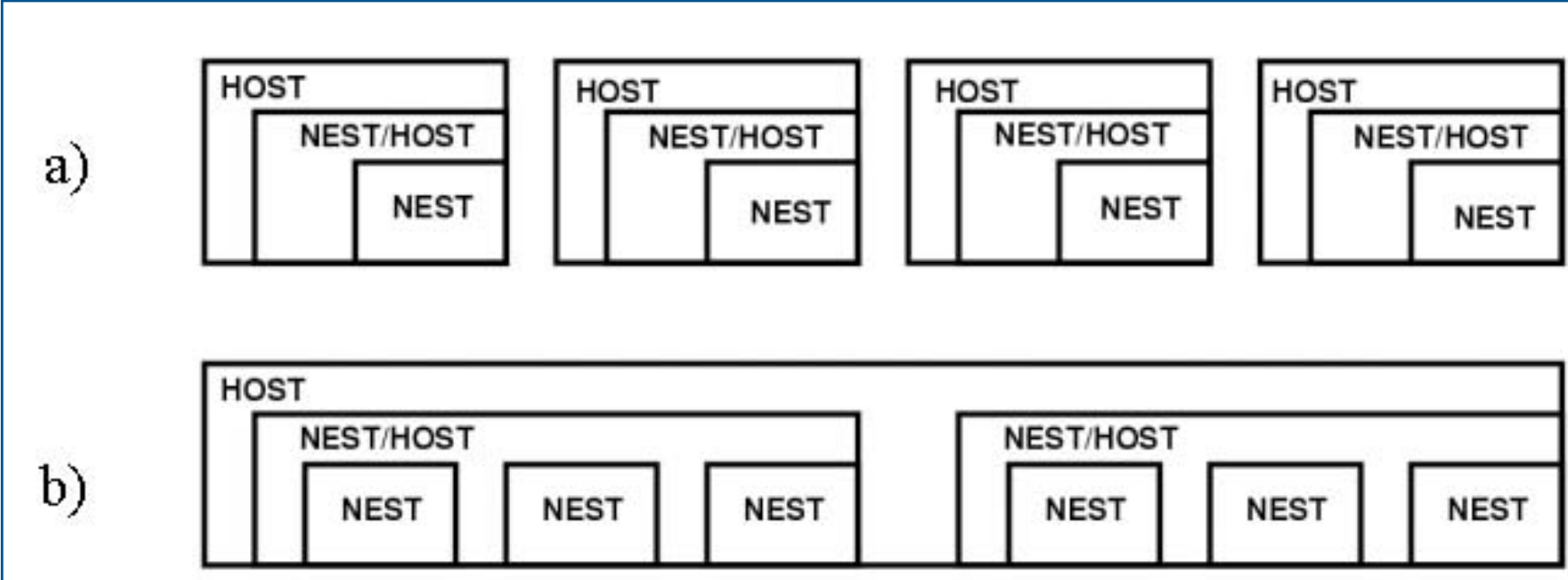

Figure 3. WAM nesting $\boldsymbol{a}$ ) stovepipe approach to model domain set up in which a host is required for every nest. $\boldsymbol{b}$ ) improvements allow multiple nests to be run from a single host.

be accomplished in a few minutes. Also, more and larger domains can run on the computational machine in less time.

For Navy applications, Basin scale WAM runs are forced with the Navy Operational Global Atmospheric Prediction System (NOGAPS), which has a horizontal resolution of $1.0^{\circ}$. For embedded nests of higher resolution (generally $\leq 1 / 4^{\circ}$ ) winds from the Coupled Ocean Atmospheric Mesoscale Prediction System (COAMPS) are used when available.

Regional domains cover large areas such as the entire Mediterranean Sea at a $0.1^{\circ}$ grid spacing and as small as 1-minute domains about the Hawaiian Islands. Other regions include the seas around North and Central America, the Indian Ocean, the Asian Pacific, Indonesia, and seas surrounding the Australian continent. WAM output is then post-processed to provide over a hundred sets of tailored graphics products on the World Wide Web (Figure 4, see also http:/ / www.navo.navy.mil) for access to the warfighter. Products include a rendering of significant wave height, primary wave direction, swell height and direction, and wave period. These parameters are calculated from the model's computational arrays' (of discrete frequency and direction) spectral values. These values are passed from host to nests as boundary conditions. Also, WAM passes spectral values as boundary conditions to shallow-water wave models such as STWAVE.

WAM at NAVOCEANO has been enhanced for increased throughput and greater flexibility to run on many domains and to provide the input for littoral, shallow-water model predictions anywhere in the world. In the future, WAM will be ported on to new architectures such as the IBM-SP and LINUX PCs. These increased capabilities, current and planned, will be integrated into the IOPS wave-tide-surf modeling system.

\section{Shallow-Water Wave Models}

The IOPS model suite utilizes two shallow-water wave model options: (1) STWAVE and (2) REFDIF. STWAVE can generate 2-D outputs of significant wave height, peak period, and mean wave direction. Directional wave spectra saved at user-specified locations can be used for generating subsequent surf forecasts. In another IOPS application, REFDIF can generate shallow-water wave spectra when wind is not a factor, since the model does not include wind effects. Utilizing a linear transfer coefficient technique, WAM deep-water wave spectra are transformed to shallowwater wave spectra. While this approach can require extensive computations to derive these coefficients, the payoff is at operational run-time, when accurate results can be produced in a few minutes, versus hours. The following section gives a more detailed description of these two shallow-water wave models.

\section{STWAVE}

The Steady-state spectral Wave model (Resio 1987, 1988a, 1988b; Smith et al., 1999) is a steady-state finitedifference model based on the wave-action balance equation. STWAVE is a half-plane model, which considers wave energy propagating from the offshore toward the nearshore from the x-axis of the grid, which is typically the approximate shore-normal direction. STWAVE can simulate depth-induced wave refraction and shoaling, current-induced refraction and shoaling, depth- and steepness-induced wave breaking, diffraction, wind-induced wave growth, and wave-wave interaction and white capping that redistribute and dis- 


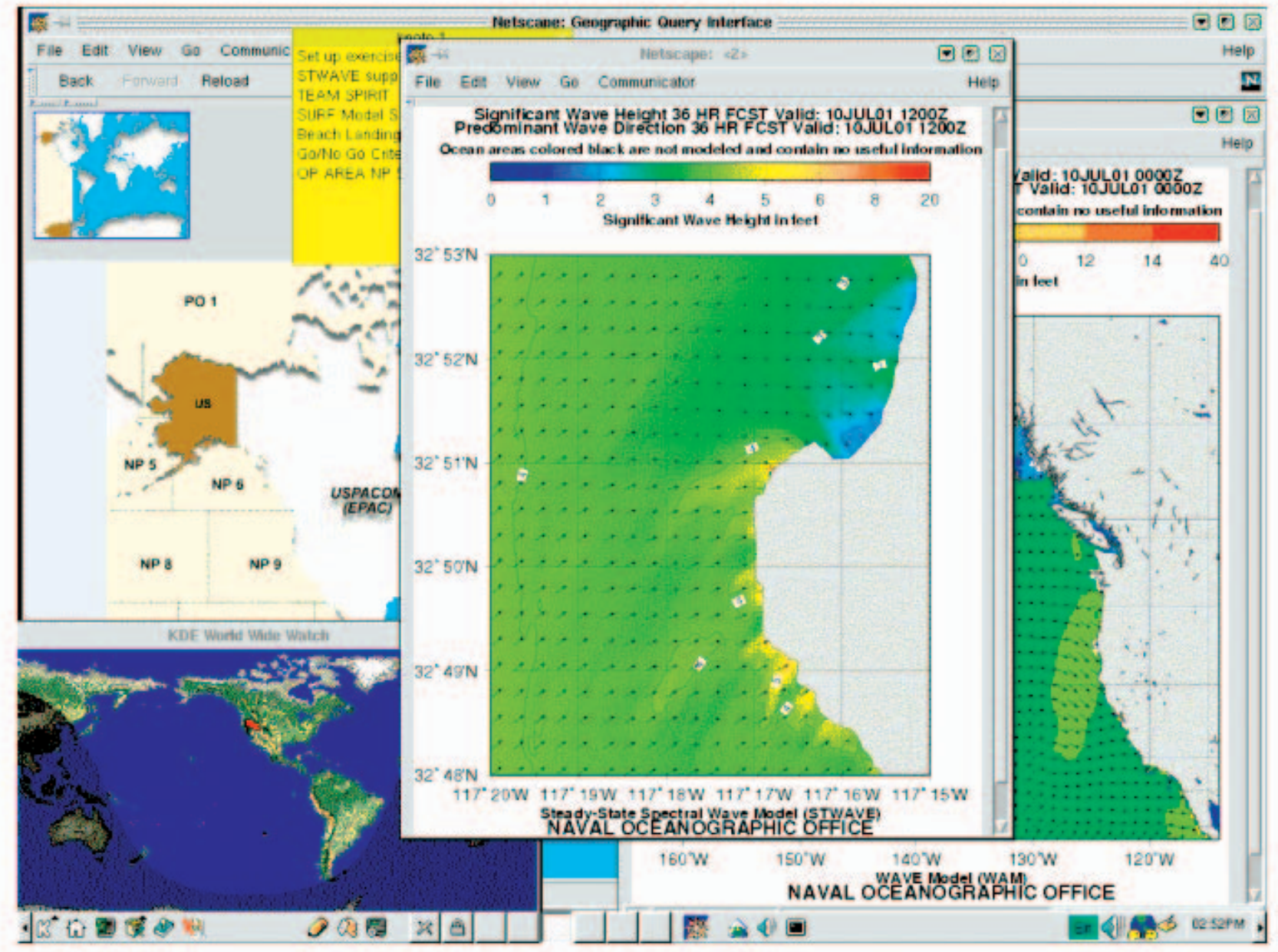

Figure 4. Standard ocean surface wave forecast products used by the warfighter as provided by the Warfighting Support Center at the U.S. Naval Oceanographic Office.

sipate energy in a growing wave field.

STWAVE assumes that offshore wave conditions are homogenous. Thus, the wave energy (provided from a regional WAM) is held constant on the domain's offshore boundary. The steady-state formulation reduces computational time and is appropriate for wave conditions that vary more slowly than the time it takes for waves to travel across the computational grid.

STWAVE includes a wave-current interaction feature based on a barotropic or depth-averaged current. If strong vertical gradients in the current occur, their modification of shoaling and refraction will not be represented in the model.

A finite-difference model, STWAVE, is formulated for a Cartesian coordinate system using square grid cells $(\Delta x=\Delta y)$. STWAVE operates in a local coordinate system with the $\mathrm{x}$-axis oriented in the cross-shore direction and the y-axis oriented along-shore. The yaxis is usually aligned with the bottom contours along the outer boundary of the grid. In a standard IOPS implementation, a STWAVE grid may be set up for an area of coastline ranging from $15-30 \mathrm{~km}$ along-shore and $10-20 \mathrm{~km}$ in the cross-shore. To run a subsequent surf model application, a series of locations is specified in which shallow-water wave spectra are to be saved.

\section{REFDIF}

The REFDIF model of Kirby and Dalrymple (1994) incorporates the effects of shoaling, refraction, energy dissipation, and diffraction on the propagation of water waves over a field of irregular depths and around irregularly shaped islands. In an IOPS application, REFDIF is employed to produce linear transfer functions for refraction and shoaling that are used to modify offshore (WAM) directional wave spectrum to wave conditions found very nearshore, suitable for initializing the surf model.

Running wave models such as REFDIF each time for new boundary forcing can be a time consuming process. A transfer function approach can be applied 
for wave hindcasts, nowcasts, or forecasts and can greatly reduce run time. In this approach, calculations are made in advance for all possible frequency and angular components, and the results are saved in a tabular form. A set of transfer functions (one each for shoaling and refraction) are produced for a given location, and remain valid until significant changes in the nearshore depth occur, for example, after a major storm. The transfer function consists of two rectangular matrices. Each element of the matrices corresponds to a unique wave frequency and direction. The first matrix consists of amplitude coefficients, representing the change in amplitude for a wave with a given frequency and direction from the offshore boundary of the model to a nearshore location. The second matrix consists of directions representing the change in direction for a given wave. To modify a complete directional wave spectrum, the amplitudes and directions of individual wave components are modified by the corresponding transfer functions and then linearly combined with results from other components. An example of this technique is shown in Figure 5 in which an incoming wave at a water depth of $100 \mathrm{~m}$ with a period of $10 \mathrm{sec}-$ onds and an offshore wave direction of $-30^{\circ}$, is refracted to a wave angle of $-14.3^{\circ}$ at a water depth of $9 \mathrm{~m}$.
O'Reilly and Guza (1993) have successfully applied this superposition approximation (valid only where there is no wave breaking) to provide swell forecasting in the Southern California Bight. Kaihatu et al. (1998) examined phase-resolving models for a narrow shelf and smooth bathymetry near Oceanside, California, and an East Coast site at Camp Lejeune, North Carolina, with fairly complex bathymetry and distinct bottom features. They concluded that phase-resolving models such as REFDIF offer an accurate description of monochromatic swell wave propagation over highly variable bathymetry, but care must be given in how the incoming wave spectra are discretized. Since REFDIF does not account for wind-induced processes, the model is considered valid only during periods when wind flows are of moderate strength or less, or in a fetch-limited situation, where the model is applied to a relatively small geographic area (e.g. a coast with a narrow continental shelf).

\section{Tide Models}

A typical IOPS implementation utilizes a tide model to provide tidal predictions for surf locations of interest. IOPS provides two tide model options: ADCIRC or PCTIDES. ADCIRC is run on an unstruc-
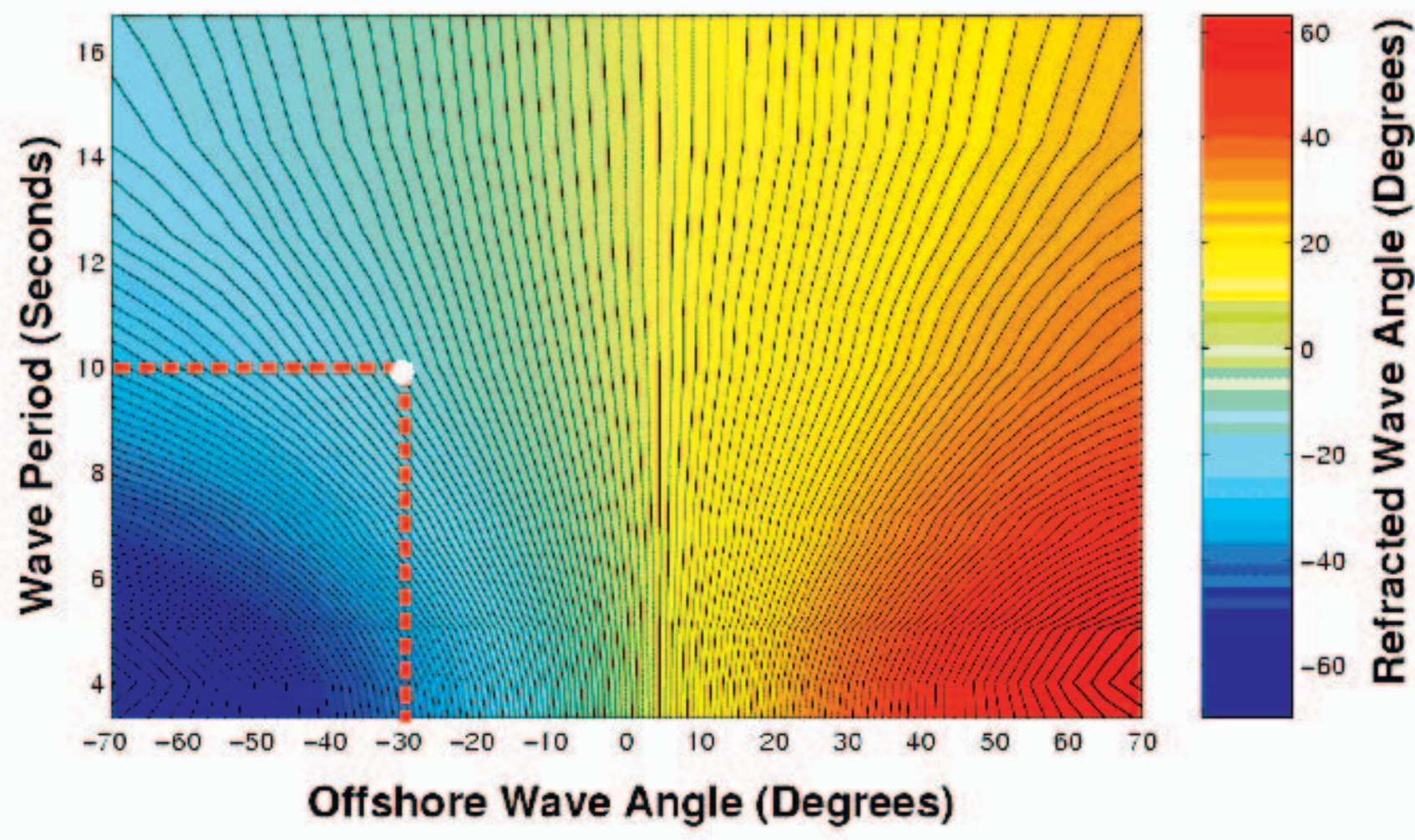

Figure 5. Example of REFDIF refraction coefficients; incoming wave has a period of 10 seconds and wave direction of -30'; the modified wave direction is $-14.3^{\circ}$. 
tured grid, requiring more expertise by the user to properly set up the grid and apply appropriate tidal constituent boundary conditions. An advantage in running ADCIRC, however, is that its triangular mesh allows one to resolve coastal features and inlets at very high resolutions (on the order of meters, if desired), while a region far removed from the area of interest can be resolved on scales of tens of kilometers. PCTIDES is much easier to set up since the grid spacing is equidistant $(\Delta x=\Delta y)$. The following section provides background information on these models.

\section{ADCIRC}

ADCIRC-2DDI (Luettich et al., 1992) is a 2-D barotropic (depth-averaged) hydrodynamic model that calculates water surface elevations and depth-averaged currents in the nearshore on a finite-element grid. The inputs required to run ADCIRC include:

- Bathymetry and shoreline position

- Specification of a finite-element grid and boundary conditions,

- Tidal constituents along the grid boundary, and

- Wind speed and direction and atmospheric pressure.

ADCIRC has the capability of activating the wetting and drying of computational grid cells. The model is also used for both tidal and storm surge simulations (Blain et al., 1994). A more detailed description of ADCIRC can be found in this publication (Blain et al., this issue).

In an IOPS framework, when a surf model run is being set up, the ROAMER relational database is queried to determine if an ADCIRC grid supports the set of water level locations requested by the user. If an ADCIRC grid exists, a series of locations (latitude, longitude) are passed to an ADCIRC post-processor, which interpolates ADCIRC water elevations from the finite-element grid to the desired location. If the requested grid points do not fall within the ADCIRC domain, then another tidal-prediction model, such as PCTIDES is used.

\section{PCTIDES}

PCTIDES is a globally relocatable tidal-prediction model, which consists of a 2-D barotropic ocean model. Originally designed for a PC-based environment, PCTIDES has been configured to run on UNIX platforms. Surface winds and pressures and/or astronomical tides are used to force the model. A global tide model, the Finite Element Solutions 95.1/2.1 (FES95.1/2.1), is used to provide tidal conditions on open boundaries. All databases, except for wind and pressure forcing, are internal to PCTIDES. These databases include: (1) bathymetry, a 3-minute interpolated version of DBDB-V, (2) the FES95.1/2.1 solutions, and (3) a tidal station database consisting of more than 4200 stations from the International Hydrographic Office (IHO) database. The IHO data can be used for either model validation or for data assimilation.

PCTIDES can be configured to run "stand-alone" or in a nested fashion. Generally, a nested region covers an area smaller than the host grid but with a resolution 3 to 4 times higher. The IOPS user can select wind forcing from NOGAPS, which provides truly global coverage with a horizontal resolution of $1.0^{\circ}$. NOGAPS is used if wind forcing is important, but no higher-resolution wind fields are available. However, the U.S. Navy provides higher-resolution COAMPS forcing fields for many geographic regions of interest. More detailed information about PCTIDES can be found in this issue (see Blain et. al).

Under IOPS, PCTIDES is used to provide a waterlevel time series (e.g. a 48-hour forecast) for any location where a surf forecast is to be made.

\section{Surf Modeling}

The NSSM has been used extensively throughout the U.S. Fleet since it was first introduced in the late 1980s. The model is the primary software for Navy operational surf forecasting, and it is also used for system development and surf climate descriptions. NSSM has gone through several improvements. Earle (1999) provides a model overview and examples of its applications. Further application of NSSM coupled to other wave and tide models can be found in Allard et al. (1999).

NSSM produces outputs that meet the operational requirements as described in the Joint Surf Manual (Commander, Naval Surface Force, Pacific and Commander, Naval Surface Force, Atlantic,1987). Model outputs include the following:

- A forecast summary, which lists the surf zone width, the maximum wave height and long shore current, direction of breakers, breaker type, breaker period, and the Modified Surf Index (MSI), which is a dimensionless number that characterizes overall surf conditions.

- An optional listing of depth, wave height, wavelength, percent of breaking waves, and longshore current as function of distance off shore.

\section{Computations of Wave Height and Longshore Current}

Hsu et al. (2000) present an updated description of the NSSM theory, equations, and numerical methods; thus, only a brief description of the model is given herein. The model is parametric and one-dimensional, and is largely based on Thornton and Guza formulation $(1983,1986)$. The wave height in the surf zone is computed based on the energy flux balance. The energy flux equation balances the wave and roller fluxes of energy density to energy dissipation due to the depthinduced breaking. The model uses wave-roller dissipation developed by Lippmann et al. (1996). Main assumptions in the surf model are: (1) straight and parallel bottom contours and (2) narrow banded waves (i.e. single-peak wave frequency). 
Longshore current calculations are based on radiation-stress longshore current theory first developed by Longuet-Higgins $(1970 a, b)$. The momentum conservation equation considers the production of momentum fluxes from breaking waves and wind, horizontal turbulent mixing, and bottom friction. Recently, Hsu et al. (2000) have shown that the longshore current estimates can be considerably improved by making relatively simple changes to bottom friction formulation. After the bottom friction coefficient in the model is changed to a depth-dependent bottom friction function, the longshore current estimates are significantly improved. It should be noted that the variable bottom friction function reflects the shoreward increase in friction due to sediment sorting and compensates for the lack of vertical eddy diffusivity in one-dimensional models.

\section{NSSM Model Validation}

NSSM has been validated extensively (Mettlach et al, 2000) with data collected from field studies and laboratory experiments. Figure 6a shows a plot of longshore current from measurements taken during the DELILAH and DUCK94 experiments versus NSSM using optimal bottom friction and horizontal mixing coefficients. Figure $6 \mathrm{~b}$ shows very good agreement with NSSM wave height versus observations. This study shows that with accurate inputs to the model, NSSM can provide skill in the depiction of surf conditions.

\section{NSSM Inputs}

IOPS is an integrated system providing the hooks required to generate a surf forecast. The following section describes the necessary inputs required to run NSSM.

Directional Wave Spectra: NSSM is initialized with directional wave spectra obtained from one of the two shallow-water wave models, STWAVE or REFDIF. Spectra are saved at water depths of approximately 7-9 $\mathrm{m}$, just outside of the surf-zone where wave breaking has not occurred.

Tides: Water level information provided by ADCIRC or PCTIDES is input to NSSM to adjust the beach profile. Surf forecasts are generally made for 48hour periods; a tidal prediction with a temporal resolution of at least 6 hours is most commonly used.

Winds: $10-\mathrm{m}$ surface winds fields are input into NSSM and used in the calculation for the longshore current. The default model for wind input is NOGAPS. Otherwise, COAMPS is used.

Beach Profiles: The user has several options available to incorporate a beach profile(s) into the model. A nearshore depth profile extends from land to a water depth of about $8 \mathrm{~m}$. Some of the beach profile options are discussed below:
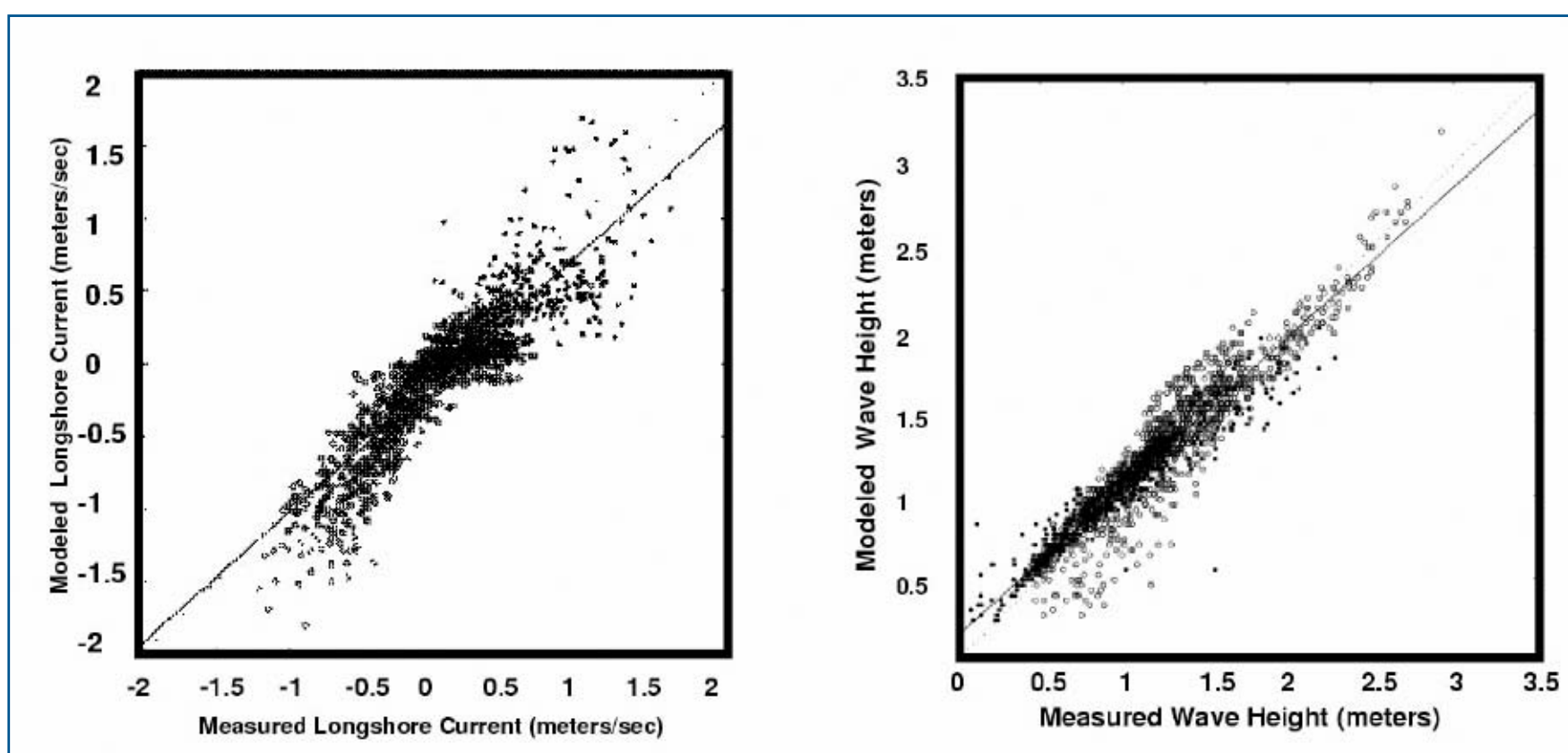

Figure 6. Scatter diagram of a) measured longshore current vs. corresponding model estimates of current. Observed data are from DELILAH and DUCK94 measurements. Based on 1930 observations, the linear correlation coefficient is 0.89 with a standard deviation of $0.22 \mathrm{~m} / \mathrm{s}$. b) measured root-mean wave heights vs. estimates of wave height. Based on 1796 observations, the linear correlation coefficient is 0.945 with a standard deviation of $0.15 \mathrm{~m}$. 


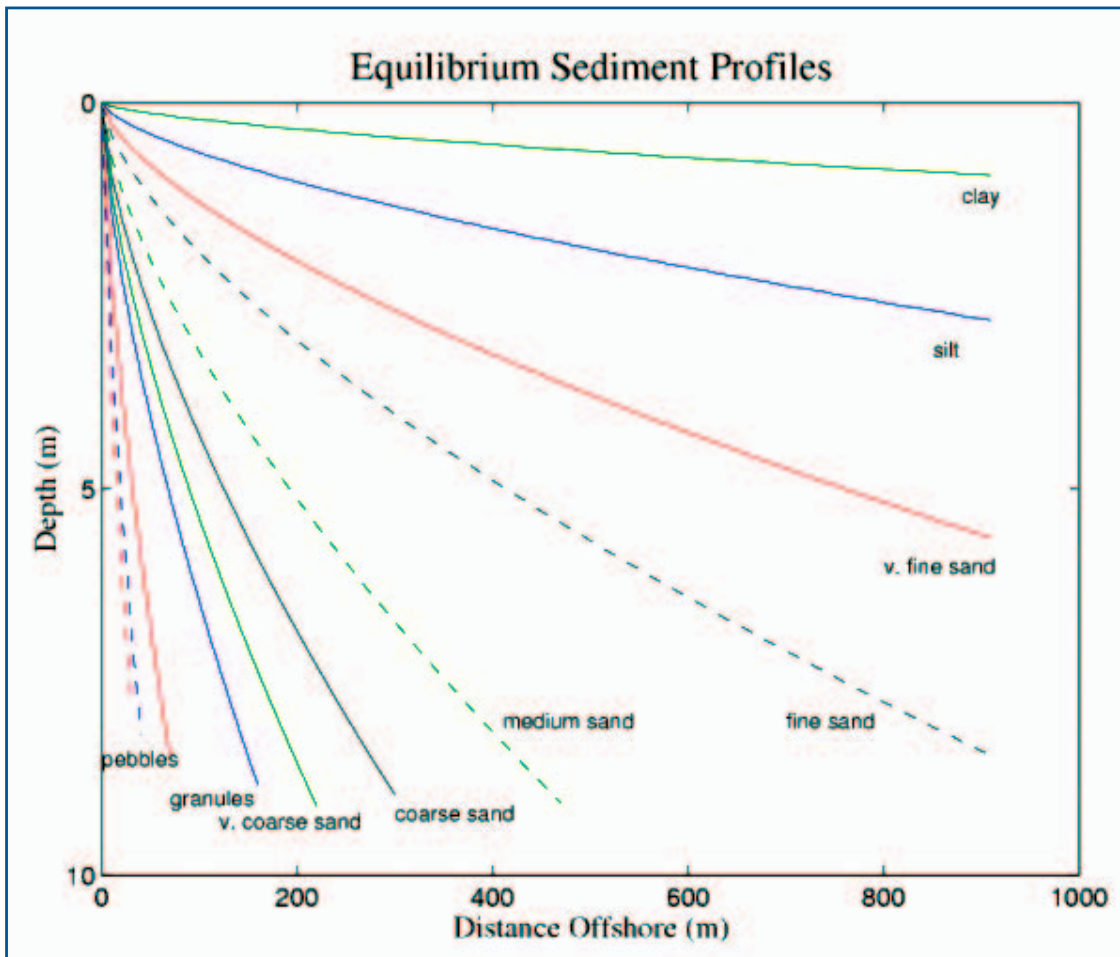

Figure 7. Equilibrium beach profiles

Imported Beach Profiles: IOPS allows a user to import beach profiles collected from a variety of sources including Sea Air Land (SEAL) team beach surveys and those collected from systems such as the Scanning Hydrographic Operational Airborne Lidar Survey (SHOALS). During the Rapid Environmental Assessment phase of NATO Linked Seas 2000 Exercise near Pinheiro da Cruz, Portugal, SHOALS was used to collect beach profiles. Operating on a fixed-wing Twin Otter aircraft at an altitude of $300 \mathrm{~m}$, SHOALS (Lillycroft et al., 2000) was used to collect nearshore bathymetry with a resolution for each beach sounding of $4 \mathrm{~m}$. The NAVOCEANO WSC utilized the SHOALS data in providing wave and surf forecasts to support the exercise.

\section{NSSM Output}

An example of NSSM output depicted in Figure 8 a-e shows a 48hour time series of surf-related parameters from the IOPS coupled wave-tide-surf modeling system. If a

Equilibrium Beach Profile: An equilibrium beach profile (Dean, 1977) based on sediment type (and grain size) is the default, if no other information is available. In the Dean study, 502 beach profiles from the U.S. East Coast and Gulf of Mexico were examined. Figure 7 shows equilibrium beach profiles based on grain sizes ranging from pebbles to very fine sand and clay.

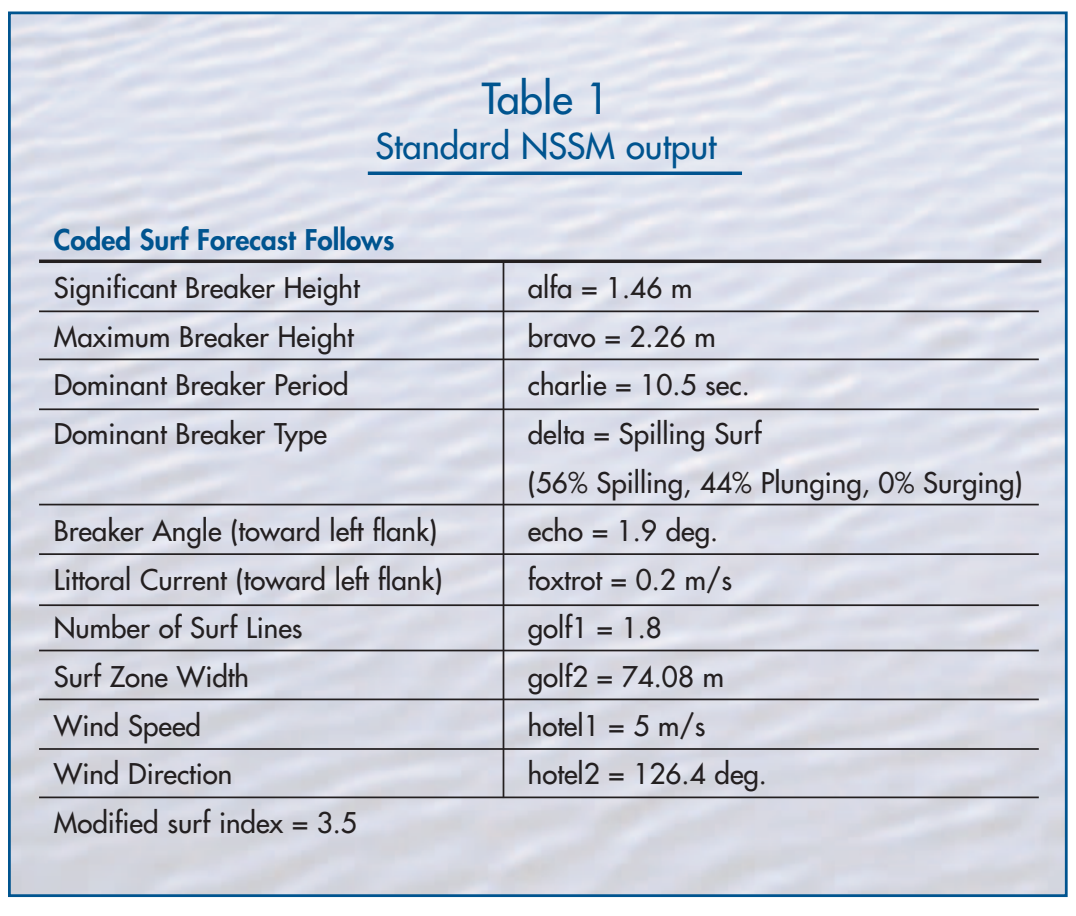

landing is being considered for several beaches, this forecast can be used as a tool to determine the best location based on predicted surf conditions. A text version of NSSM output is shown in Table 1. The Modified Surf Index (see Table 1) can be used by mission planners to determine if surf conditions are near or exceed critical levels based on the type of landing craft.

\section{Summary and Future Plans}

An integrated modeling approach has been described in which the deep-water WAM is coupled to shallow-water wave, tide, and surf models. The system is designed to be modular in fashion so that improvements or replacements for the modules can be incorporated. IOPS software and documentation was delivered to NAVOCEANO in December 2001. Testing and evaluation of the system began in January 2002.

Future plans include integrating the Simulating WAves Nearshore (SWAN) wave model into IOPS. SWAN includes improved approaches for wave propagation and an ability to operate efficiently on very fine grid meshes (order $100 \mathrm{~m}$ or less). It is a full plane model (onshore and offshore winds and waves) and has both time-dependent and steady-state modes. The model is designed to nest with WAM. SWAN has undergone significant testing 
(a)

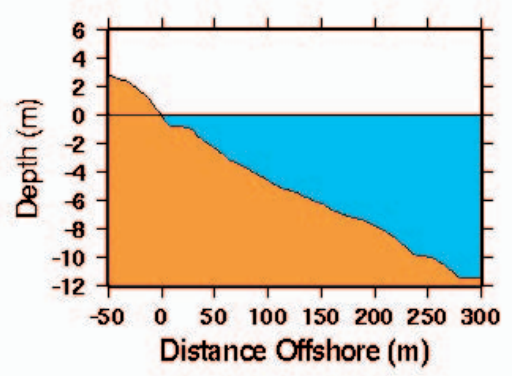

(d)

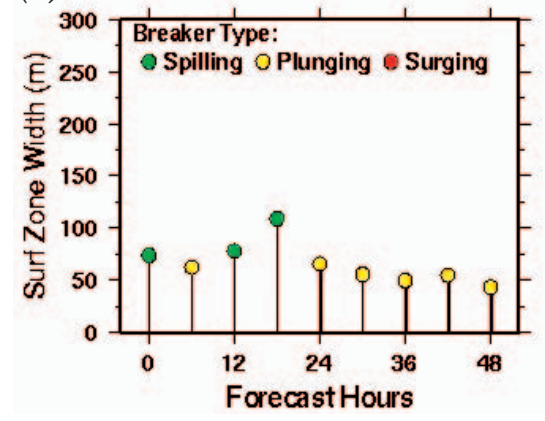

(b)

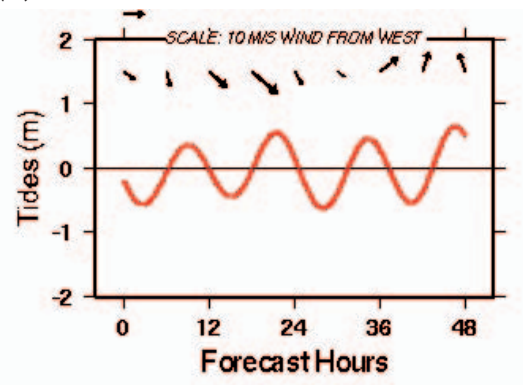

(e)

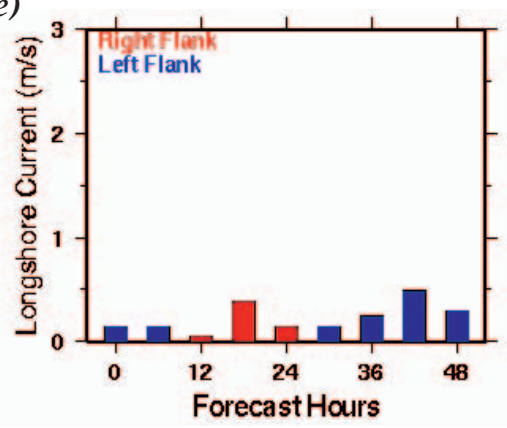

(c)

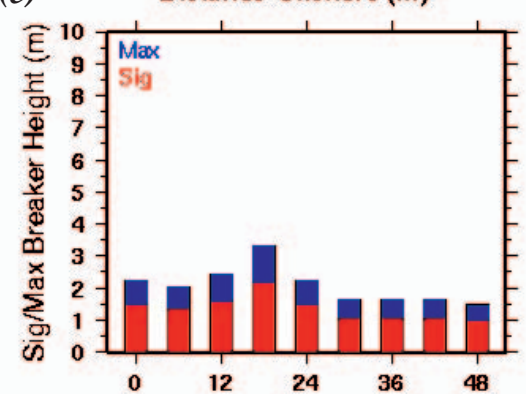

(f)

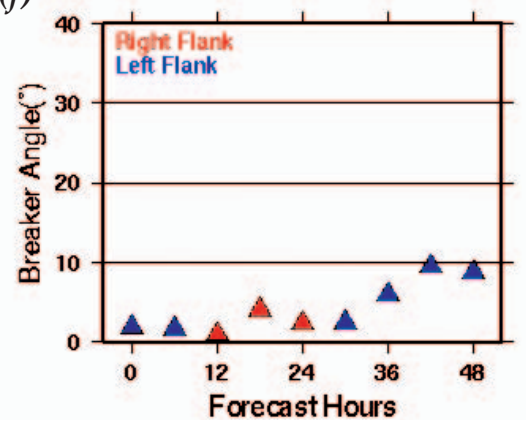

Figure 8. Surfforecast for a potential landing beach: $\boldsymbol{a}$ ) beach profiles used in the surf calculation, $\boldsymbol{b})$ tidal prediction with forecast 10-m winds, $c$ ) significant /maximum breaker heights within the surf zone, d) surf zone width and breaker type, e) longshore current and $f$ ) breaker angle.

(perhaps the most extensive testing of any shallowwater wave model) and has an international user base of over 100 users. The model is well documented. SWAN is being run to support the Northern Gulf Littoral Initiative (NGLI) in the Mississippi Bight. Plans are underway to begin an evaluation and commence testing of SWAN at NAVOCEANO.

A distributed IOPS (DIOPS) has been installed at the Navy Pacific Meteorology Oceanography Center in San Diego, California. DIOPS allows a user to run a host of models in an object-oriented environment on a UNIX workstation. Atmospheric forcing and bathymetry are accessed through the U.S. Navy's Tactical Environmental Data Server (TEDS). It is anticipated that directional wave spectra from NAVOCEANO's Regional WAM model will be distributed via TEDS to initialize DIOPS shallow-water wave models, ultimately providing situational awareness of the littoral and surf environmental conditions to the warfighter ondemand. ब्य

\section{Acknowledgments}

This work has been funded through the Space and Naval Warfare Systems Command (PMW 155) (program element $603207 N$ ). This paper, NRL contribution
NRL/JA/7320/01/0016, is approved for public release, distribution unlimited.

\section{References}

Allard, R.A., Y.L. Hsu, K. Miles, T. Mettlach and M.D. Earle, 1999: Toward an operational coupled wave/surf forecasting system. In: Proc. Third Conference on Coastal Atmospheric and Oceanic Prediction Processes, American Meteorological Society, New Orleans, 350-355.

Blain, C.A., J.J. Westerink and R.A. Luettich, 1994: The influence of domain size on the response characteristics of a hurricane storm surge model. J. Geophys. Res., 99, 18, 18467-18479.

Commander, Naval Surface Force, Pacific and Commander, Naval Surface Force, Atlantic,1987: Joint Surf Manual, COMNAVSURFPAC/ COMNAVSURFLANTINST 3840.1B, 02 January 1987, 13 chap.

Dean, R.G., 1977: Equilibrium beach profiles: U.S. Atlantic and Gulf Coasts. Ocean Engineering Technical Report 12, Department of Civil Engineering and College of Marine Studies, University of Delaware.

Earle, M.D., 1999: Applied and operational surf modeling. Shore and Beach, 67, 70-75. 
Hsu, Y.L., T.R. Mettlach and M.E. Earle, 2000: Improvement and Validation of the Navy Longshore Current Model. NRL/FR/7320-00-9927, $46 \mathrm{pp}$.

Kaihatu, J.M., W.E. Rogers, Y.L. Hsu and W.C. O'Reilly, 1998: Use of phase-resolving numerical wave models in coastal areas. In: Proc. $5^{\text {th }}$ International Workshop on Wave Hindcasting and Forecasting, Environment Canada, Melbourne, FL, 389-403.

Kirby, J.T. and R.A. Dalrymple, 1994: Combined Refraction-Diffraction Model REF/DIF1, version 2.5, documentation and user's manual. Report 9422, Center for Applied Coastal Research, University of Delware, $177 \mathrm{pp}$.

Komen, G.J., L. Cavaleri, M. Donelan, K. Hasselmann, S. Hasselmann and P.A.E.M. Janssen, 1994: Dynamics and Modeling of Ocean Waves. Cambridge University Press, Cambridge, U.K., 532 pp.

Lillycroft, W.J., R.W. Pope and G.R. West, 2000: GPS sends in the marines, rapid environmental assessment with LIDAR. GPS World, November 2000, 8 pp.

Lippmann, T.C., A.H. Brookins and E.B. Thornton, 1996: Wave energy transformation on natural profiles. Coastal. Eng. , 27, 1-20.

Longuet-Higgins, M.S., 1970a: Longshore currents generated by obliquely incident sea waves, 1. J. Geophys. Res., 75(33), 6678-6789.

Longuet-Higgins, M.S., 1970b: Longshore currents generated by obliquely incident sea waves, 2. J. Geophys. Res. 75(33), 6790-6801.

Luettich, R.A., Westerink, J.J. and N. Sheffner, 1992: DCIRC: an advanced three-dimensional circulation model for shelves, coasts, and estuaries, Report 1: theory and methodology of ADCIRC-2DDI and ADCIRC-3DL. Technical Report DRP-92-6, U.S. Army Engineer Waterways Experiment Station, Vicksburg, MS.

Mettlach, T.R., Y.L. Hsu, M.D. Marshall and E.D. Osiecki, 2000: Application of the Navy standard surf model: SURF 3.1. In: Proc. 6th International Workshop on Wave Hindcasting and Forecasting, Environment Canada, Monterey, 380-391.

O'Reilly, W.C. and R.T. Guza, 1993: A comparison of two spectral wave models in the southern California bight. Coastal Eng., 19, 263-282.

Resio, D.T., 1987: Shallow-water waves I: Theory. J. Wtrway., Port, Coast., and Oc. Engrg., ASCE, 113(3), 264-281.

Resio, D.T., 1988a: Shallow-water waves II: Data comparisons. J. Wtrway., Port, Coast., and Oc. Engrg., ASCE, 114(1), 50-65.

Resio, D.T., 1988b: A steady-state wave model for coastal applications. In: Proc. $21^{\text {st }}$ Coast. Engineering Conference, American Society of Civil Engineers, Torremolinos, Spain, pp. 929-940.

Smith, J.M., D.T. Resio and A.K. Zundel, 1999: STWAVE: Steady-state spectral wave model.
Report 1. User's Manual For STWAVE Version 2.0. Instruction Report CHL-99-1, 57 pp.

Thornton, E.B and R.T. Guza, 1983: Transformation of wave height distribution. J. Geophys. Res., 88 (C10), 5925-5938.

Thornton, E.B and R.T. Guza, 1986: Surf zone currents and random waves: field data and models, J. Phys. Oceanogr., 16, 1165-1178.

WAMDI Group, 1988: The WAM model—a third-generation ocean wave prediction model. J. Phys. Oceanogr., 18, 1775-1810. 